ISSN 0103-5150

Fisioter. Mov., Curitiba, v. 29, n. 3, p. 561-568, Jul./Set. 2016

Licenciado sob uma Licença Creative Commons

DOI: http://dx.doi.org.10.1590/0103-5150.029.003.A014

\title{
Ipsilesional upper limb performance in stroke individuals: relationship among outcomes of different tests used to assess hand function
}

\author{
Relação entre o desempenho em diferentes testes de \\ função manual de indivíduos pós acidente vascular \\ encefálico: avaliação do membro ipsilesional
}

\author{
Bianca Pinto Cunha ${ }^{[a]}$, Sandra Maria Sbeghen Ferreira de Freitas ${ }^{[b]}$, Viviana Van Den Berg de Menezes ${ }^{[b]}$, Paulo \\ Barbosa de Freitas ${ }^{[]^{*}}$ \\ [a] Universidade Cruzeiro do Sul (UNICSUL), São Paulo, SP, Brazil \\ [b] Universidade Cidade de São Paulo (UNICID), São Paulo, SP, Brazil
}

\begin{abstract}
Introduction: Stroke individuals have sensorimotor repercussions on their ipsilesional upper limb. Therefore, it is important to use tests that allow an adequate assessment and follow-up of such deficits. Physical and occupational therapists commonly use maximal grip strength tests to assess the functional condition of stroke individuals. However, one could ask whether a single test is able to characterize the hand function in this population. Objective: The aim of this study was to investigate the relationship among outcomes of different tests frequently used to describe the function of the hand in the ipsilesional upper limb of stroke individuals. Methods: Twenty-two stroke individuals performed four hand function tests: maximal handgrip strength (HGSMax), maximal pinch grip strength (PGSMax), Jebsen-Taylor Hand Function Test (JTHFT) and Nine Hole Peg Test (9-HPT). All tests were performed with the ipsilesional hand. Pearson's correlation analyses were performed. Results: the results indicated a moderate and positive relationship between HGSMax and JTHFT ( $\mathrm{r}=0.50)$ and between JTHFT and 9-HPT ( $\mathrm{r}=0.55)$. Conclusion: We conclude that the existence of only moderate relationships between test outcomes demonstrates the need to use at least two instruments to better describe the ipsilesional hand function of stroke individuals.
\end{abstract}

Keywords: Stroke. Hand. Disability Evaluation.

\footnotetext{
*BPC: Doctoral Student, e-mail: cunha.bp@gmail.com

SMSFF: PhD, e-mail: smsf.freitas@gmail.com

VVDBM: MS, e-mail: vivi_vbm@hotmail.com

PBF: PhD, e-mail: paulo.defreitas@pq.cnpq.br
} 
Resumo

Introdução: Indivíduos que sofreram um acidente vascular encefálico (AVE) apresentam repercussões sensoriomotoras em membro superior ipsilesional, se tornando importante a utilização de testes que possibilitem a avaliação e o acompanhamento adequado de tais déficits. Profissionais da reabilitação, como fisioterapeutas e terapeutas ocupacionais, comumente utilizam testes de força de preensão máxima para avaliar as condições funcionais de indivíduos após um AVE. Porém, será que apenas um teste é capaz de caracterizar a funcionalidade das mãos? Objetivo: $O$ objetivo desse estudo foi examinar a relação do desempenho entre testes comumente utilizados para descrever a função manual do membro ipsilesional de indivíduos que sofreram um AVE. Métodos: Vinte e dois indivíduos pós AVE realizaram quatro testes: força de preensão palmar máxima (FPPMax), força de preensão digital máxima (FPDMax), teste de função manual Jebsen-Taylor (TFMJT) e teste dos nove pinos nos buracos (9-PnB). Todos os testes foram realizados com a mão ipsilesional. Foram realizados testes de correlação de Pearson entre os resultados obtidos em cada teste. Resultados: Os resultados indicaram uma relação positiva e moderada apenas entre TFMJT e FPPMax $(r=0,50)$ e entre o desempenho no TFMJT e no teste dos 9-PnB $(r=0,55)$. Conclusão: Conclui-se que a existência de relações de fraca a moderada demonstra a necessidade de utilização de pelo menos dois instrumentos, para que se possa descrever melhor a funcionalidade das mãos de indivíduos pós AVE.

Palavras-chave: Acidente Vascular Cerebral. Mãos. Avaliação da Deficiência.

\section{Introduction}

Most people affected by a stroke have difficulties performing activities of daily living (ADL) requiring the upper limb due to the repercussions of the disease. Included among these difficulties are: decreased range of joint motion, muscle weakness, abnormal muscle tone, and sensory deficits $(1,2)$. These changes cause motor deficits and lead to the affected individuals to lose their autonomy and independence. Fifty-five to $75 \%$ of those individuals affected by a stroke tend to have enduring consequences arising from the brain injury (3) which are more evident in the body side contralateral to the affected cerebral hemisphere (4). However, deficits in the ipsilesional hemisphere, considered "healthy", or "less affected", are also observed (5 - 8). For example, following a stroke, people have an inferior performance when using the ipsilesional upper limb in reaching tasks $(9,10)$ or even in clinical tests $(7,8,11,12)$, when compared to those who have not had a stroke.

The deleterious effects of stroke on the planning and coordination of the movements of the ipsilesional limb have been attributed to the anatomy and physiology of the corticospinal tract, the primary pathway responsible for sending motor commands directly from the cerebral cortex to the spinal cord. Although most fibers comprising this tract cross to the opposite side of the body, a portion of those do not, therefore they go to the ipsilateral periphery (13). Although the occurrence of an injury in a given hemisphere also influences the ipsilesional limb, the impact of a stroke on the performance of the upper ipsilesional limb in functional tasks still requires better description. Therefore, the assessment of general conditions of the upper limbs of these people is necessary, in order to track their needs and guide physiotherapists and occupational therapists in the rehabilitation methods that best suit both the contralesional, as well as the ipsilesional, upper limbs. From a clinical point of view, this knowledge is important, given that the ipsilesional limb takes over much of the manipulation tasks performed by people after a stroke on a daily basis.

Some tests for the assessment of hand function have been applied by physiotherapists and occupational therapists in people who have had a stroke (14 - 16). Among them, the tests that assess the maximum handgrip strength or maximum pinch strength (HGSMax or PGSMax) are widely used, both in research $(17,18)$ and in clinical evaluations, as indicators of hand function. One of the most frequently used tools to measure HGSMax is the Jamar ${ }^{\circledR}$ hydraulic hand dynamometer (19 - 22). However, most daily tasks do not require the use of maximum strength for their performance. In fact, hardly anyone exerts a maximum or near maximum grip strength while 
performing activities of daily living, Even if at some point someone does use maximum strength, he/she cannot keep it for long time. Therefore, it is possible that the evaluation of functions other than the ability to generate HGSMax is required for a complete description of the upper ipsilesional limb performance, e.g., target-directed reaching (9), object grasping and manipulation $(23,24)$. Given that the capability to generate HGSMax, as well as hand and digits dexterity, are functions that change after a stroke, would performance on only one test be sufficient for the assessment of hand function in this population, or is there a need to administer more tests to actually evaluate this function?

Recent studies have found that the HGSMax, when performed by young, healthy adults, had no relationship with digits dexterity, as measured by the performance on the Nine Hole Peg Test (9-HPT) (25), and a moderate relationship with manual dexterity or overall hand function, as evaluated by the JebsenTaylor Hand Function Test (JTHFT) (26). Based on these studies it is possible to suggest that using only the HGSMax test would not be sufficient to describe upper limb function. However, it should be noted that this relationship was tested in young, healthy adults who not only did not have apparent sensory or motor abnormalities in the upper limbs, but also the group members had small performance variability among them. Thus, the findings could not be extrapolated to people who suffered a stroke. Thus, the aim of this study was to investigate the relationship among outcomes of tests commonly used to describe hand function of the ipsilesional limb of people who suffered a stroke. If we find a significant and strong correlation between outcomes of different tests, we can conclude that the administration of only one test (namely, the simplest of them) would be enough to describe the hand function of the ipsilesional limb of a person who suffered a stroke. However, if the results indicate a lack of correlation, or even a weak correlation between those tests we could conclude that the administration of more than one test would be required to evaluate the ipsilesional hand function of people after stroke.

\section{Methods}

This was an observational, correlational study. Twenty-two individuals who experienced a single episode of ischemic stroke participated in the study, 11 with an injury in the right hemisphere and 11 with an injury in the left hemisphere (61.33 \pm 9.04 years). All participants were right-handed (as confirmed by the Edinburgh Handedness Inventory) (27) and did not have any other associated neurological damage, musculoskeletal disorders or abnormal sensitivity in the ipsilesional hemisphere. They participated in this study after reading and signing the informed consent form, according to the Research Standards with Human Beings as determined by Resolution No. 466/2012 of the National Health Council. This study was approved by the Research Ethics Committee of the São Paulo City University (protocol 13686932).

\section{Experimental Procedures}

During the evaluations, the participants were seated and all tasks were performed only using the upper ipsilesional limb (in other words, the least affected limb). The participants underwent a series of tests that evaluated different components of hand function: Jebsen-Taylor Hand Function Test (JTHFT, Sammons Preston Jebsen-Taylor Hand Function Test), the Nine Hole Peg Test (9-HPT Rolyan TM 9-Hole Peg Test, Model A8515), and evaluation of the capability of generating maximum hand and digits grip strength through palmar and pinch hydraulic dynamometers (Sammons-Preston and SAEHAN, respectively). The order of execution of dexterity tests (JTHFT and 9-HPT) was balanced, with the maximal strength tests performed last.

The JTHFT (7) consists of seven subtests, of which six (card turning, picking up small objects, stacking checkers, simulated feeding with a spoon, lifting heavy and light cans, lifting large and heavy cans) were applied in this study. The first subtest (writing) was not applied to these participants because it required knowledge of English. The participants were asked to perform each task as quickly as possible and the time taken for its execution was recorded using a digital stopwatch. The sum of the time spent to complete each of the subtests was the performance variable of each participant in the JTHFT.

For the 9-HPT test, a plastic console was used, comprising: a) a concave circular container in which nine pegs ( $6.4 \mathrm{~mm}$ in diameter and $32 \mathrm{~mm}$ length) were stored, b) nine holes $(7.1 \mathrm{~mm}$ in diameter and $13 \mathrm{~mm}$ in depth) aligned three by three and located 
next to the container with the pegs. The test consisted of placing the nine pegs in the nine holes, and then removing them immediately after placing the ninth peg. Participants were instructed to perform the task as quickly as possible, and the time taken to perform it was recorded by a digital timer. Three attempts were performed and the lowest among the three times was considered the participant's performance variable $(25,26)$.

Finally, the tests employed to measure the maximum grip strength tests (HGSMax) and maximum pinch grip strength (PGSMax) were performed by the participants. The tests were performed according to the instructions recommended by the American Society of Hand Therapists. In both tests, participants were seated with their arms to the trunk side, the ipsilesional forearm oriented horizontally (elbow at $90^{\circ}$ ) and pronated to $90^{\circ}$, with a slightly hyperextended hand. The participant was asked to perform the test applying as much force as possible, maintaining this level of strength for four seconds. Three trials were completed with each evaluation instrument, with a one-minute interval between trials. The highest HGSMax and the highest PGSMax values measured in three trials were considered the performance variable for each participant in these tests.

\section{Statistical analysis}

After testing the data for normality, Student's ttests for independent samples were performed to evaluate possible hand effect in the tests, given that 11 participants who had had the right side of the brain injured performed the tests with the right (dominant) hand and 11 participants who had had the left side of the brain damaged performed the tests with the left (non-dominant) hand. The results of these analyses showed no difference between hands on the performance of the four tests $(p>0.05)$. Thus, we performed a Pearson's correlation analysis without a distinction between the side of the brain injury $(\mathrm{N}=22)$ in order to test the relationship between the results of the tests (i.e., JTHFT, 9-HPT, HGSMax and PGSMax). The analyses were performed using SPSS statistical software (version 16.0), and the alpha value was set at 0.05 .

\section{Results}

The mean values and standard deviations of the analyzed variables were: total time taken for execution of the TFMJT subtests ( $36.14 \pm 7.29$ s); time taken for execution of the 9-HPT $(21.75 \pm 2.88 \mathrm{~s})$; HGSMax (33.92 $\pm 8.86 \mathrm{kgf})$ and PGSMax (6.17 $\pm 1.56 \mathrm{kgf})$. In Figure1, the scatter plots show the relationship between the performance variables. Regarding the Pearson's correlation tests, a significant relationship was found only between JTHFT and HGSMax [r (20) = $0.50, \mathrm{p}<0.05]$ and JTHFT and 9-HPT [r (20) $=0.55$, p < $0.05]$. There was no statistical significance for the relationships between PGSMax and JTHFT $[\mathrm{r}(20)=-0.08$, $\mathrm{p}>0.05]$, HGSMax and 9-HPT [r $(20)=0.23, \mathrm{p}>0.05]$, or HGSMax and 9-HPT [r (20) $=-0.04, \mathrm{p}>0.05]$.

a)

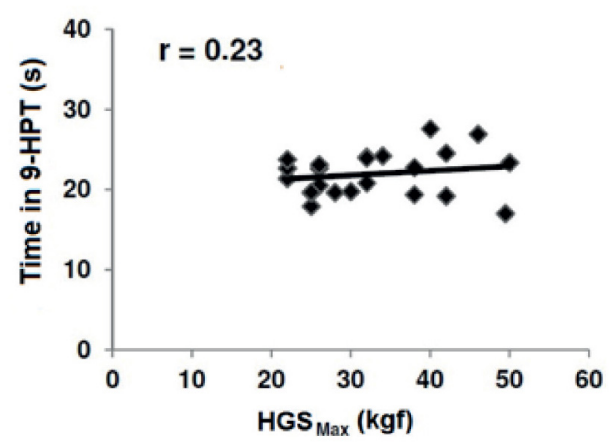

b)

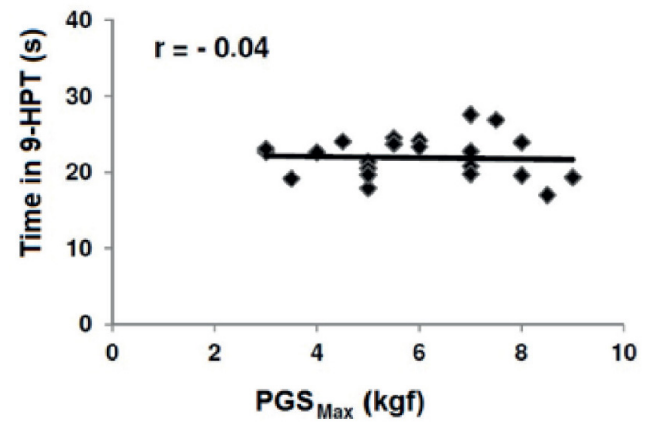

c)

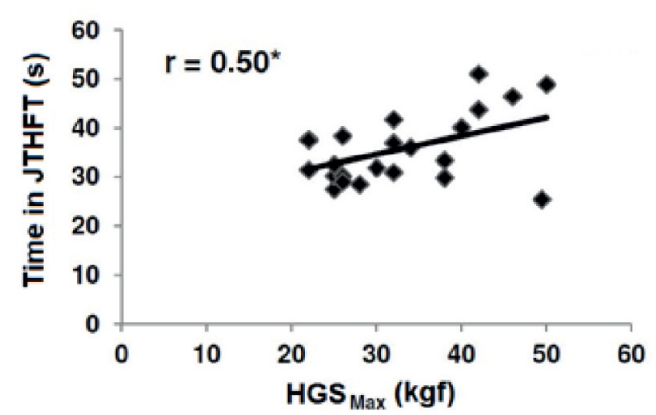


d)

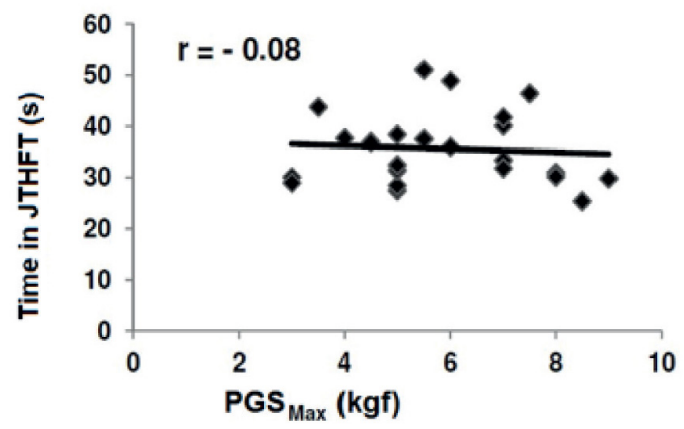

e)

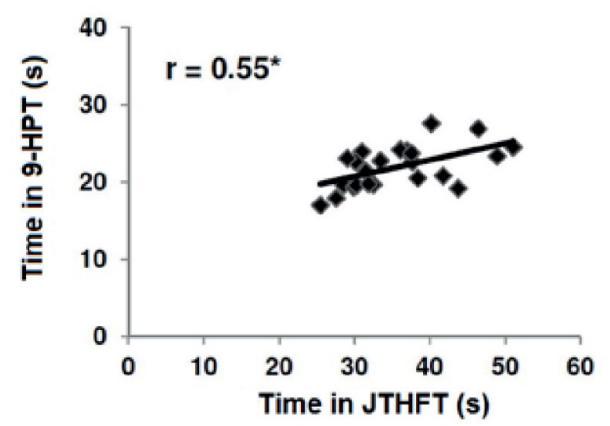

Figure 1 - Relationship between the performance variables in 9-HPT, JTHFT tests and HGSMax and PGSMax. Pearson's correlation coefficients are presented for each relationship, and the asterisk represents statistically significant relationship.

\section{Discussion}

This study examined the relationship between the performance of commonly used tests to describe hand function (JTHFT, 9-HPT, HGSMax and PGSMax) in people after stroke, using the ipsilesional hand. Of the five correlation analyses, there was a statistically significant correlation only between JTHFT and HGSMax, and between TFMJT and 9-HPT. With respect to the relationship between JTHFT and HGSMax, the relationship can be considered moderate, and it unexpectedly indicated that the higher the strength of maximum grip produced by the person after stroke, the greater the time spent (i.e., worse performance) for the execution of the JTHFT subtests. The moderate positive relationship between performance in JTHFT and 9-HPT indicated that the lower the time taken in the 9-HPT test (i.e., better performance), the lower the time taken in the JTHFT (i.e., better performance). In the following paragraphs these results are discussed separately, addressing the relationship between digits dexterity and maximum strength, hand dexterity and maximum strength, and between digits dexterity and overall hand dexterity.

Relationship between digits dexterity and maximum strength

Several activities of everyday life and work involve digits dexterity, such as buttoning a shirt, putting a needle into a specific point of the tissue, typing on a keyboard using fingertips, and others. The 9-HPT test has been widely used to evaluate digits dexterity and eye-hand coordination, because it is easy to understand, it is portable, and it has a low cost (12). Studies using this test to evaluate people after stroke concluded that it is suitable for hand function evaluation in this specific population, and it can predict their prognosis, even when the evaluated upper limb is the ipsilesional $(28,29)$. To perform the 9-HPT test, it is not necessary to apply maximum grip strength. For this reason, it is not surprising that this study found no relationship between the performance in the 9-HPT test, which evaluates digital dexterity, and the maximum strength exerted on both maximal strength tests (HGSMax and PGSMax). These findings corroborate those by Lima et al, who did not find a relationship between them when examining the performance of healthy young individuals during the tests (25).

Digits dexterity and maximum strength tests assess different characteristics of hand function. Therefore, the lack of a relationship between performances in these two characteristics of hand function should be expected. Thus, these findings highlight the need for more comprehensive clinical evaluations, contrary to what has been done in most rehabilitation clinics, where the maximum force is frequently the only evaluation of hand function used in neurological patients. Evaluating activities that require the ability to produce force in submaximal levels and to perform fast and accurate movements by using the upper limb is critical. The 9-HPT test evaluates this characteristic, given that handling small objects such as pegs requires controlling digits strength during the task, and the proper execution of the task requires precision and speed. Thus, for functional recovery of these people, digits dexterity is an important characteristic to be considered, which allows them to independently perform various activities of daily living. 
Relationship between overall hand function and maximum strength

We can use the hands to perform manipulation tasks involving refined control by using the tip of one or more digits as well as to execute tasks that require the use not only of the digits, but of the whole hand. Tests that evaluate this characteristic can indicate how functional an individual is. Thus, tests involving the execution of a list of manipulation activities can provide us with better conditions to evaluate hand function in healthy people suffering from neurological and orthopedic disorders. The evaluation of overall hand function, through the performance of JTHFT test, allows for verifying how people perform activities that require both a refined control over the manipulation of objects (i.e., subtest of picking up small objects, feeding simulation, and stacking checkers) and tasks that require a rougher grip with the use of the whole hand and greater muscle strength (i.e. subtest of handling large, heavy or light cans). The present study found a moderate relationship between HGSMax and performance in JTHFT tests ( $\mathrm{r}=0.50, p<0.05)$, and also surprisingly indicated that the higher the ability of producing maximum strength, the greater the time to perform the JTHFT, that is, the higher the strength capability, the worse the performance of the JTHFT.

These results are similar to those observed by Bonvend'Eerdt et al., who also found a moderate relationship in a study with people with neurological deficits, to verify the performance of three subtests of JTHFT and HGSMax (30). In young, healthy adults, Lima et al. also found a moderate relationship between JTHFT and HGSMax, however, unlike the findings of the present study, the authors found that the greater the person's strength, the lower the time to perform the JTHFT (26). However, in this study we found a positive relationship between the variables (the higher the strength, the longer the time spent performing the JTHFT). One possible explanation for this difference is the difficulty of individuals post stroke in controlling muscle strength during the performance of JTHFT. Thus, it is possible to suggest that individuals who could generate a greater strength had more difficulty performing JTHFT subtests in a shorter time. It should be noted that even the subtest which required greater strength for its implementation (i.e., task of lifting large and heavy cans) was not associated with the HGSMax and PGSMax.

Although the literature was not conclusive regarding the functional tests best suited for evaluating people with neurological deficits, it should be taken into account that people with a brain injury have a wide variability in their motor responses, which may have contributed to an unexpected result. The lack of indication of a strong relationship between the variables and also the different characteristics evaluated by two tests makes these forms of evaluation complementary when evaluating people after stroke, representing different characteristics of the hand function.

Relationship between digits dexterity and overall hand function

Researchers seeking answers as to what the most appropriate tests are for the evaluation of hand function have been investigating the relationships among the various clinical testing options $(16,17$, $25,26,30$ ), as was performed in the present study. The relationship between the performance of two tests that assess similar characteristics (the 9-HPT and the JTHFT) was positive and moderate $(\mathrm{r}=0.55$, $p<0.05)$. These results indicate that $30 \%$ of the variance in the JTHFT performance can be explained by digits dexterity. The result differs from those of Lima et al.'s, who found no relationship between the performance in the same tests when healthy people were examined (26). Yet, unlike Lima and colleagues, other studies evaluating people with neurological injuries concluded that there is a strong relationship among the assessed clinical tests. Therefore, the divergent results when evaluating healthy people and a population with sensorimotor deficits emphasizes the need to clearly identify the needs of the population investigated even before the choice of the method of evaluation.

The analyzed tests have speed in common. In both, it is necessary to perform the task as quickly as possible while the evaluator times it. Therefore, it makes sense that there is a significant, moderate to high, relationship between performances. Nonetheless, we cannot fail to emphasize that when performing the 9-HPT, in addition to being agile, the person must also be precise, given that its goal is to place nine pegs in nine small holes, unlike some 
tasks that are part of the JTHFT, whose main goal is just the time to grasp and place the manipulated object somewhere as quickly as possible without accuracy requirements. Therefore, identifying tests that have similar characteristics and are moderately correlated, one can select only one of the tests to assess hand function in neurological population and, specifically, in post-stroke individuals.

\section{Clinical relevance of the results}

Rehabilitation professionals have long neglected the ipsilesional limb, considering it to be a "healthy" limb and, consequently, not requiring attention during the rehabilitation process. Nowadays, results of several studies have indicated that the ipsilesional limb also has motor deficits which, although mild, can create difficulties in performing tasks of everyday life.

Thus, rehabilitation professionals increasingly have given attention to the ipsilesional limb, trying to include it in the rehabilitation process. However, effective evaluation methods are required for treatment protocols to be consistently outlined and for investigation of the success of treatment. This study aimed to examine which clinical test(s) of hand function could be used to help professionals understand the functional deficits in the ipsilesional upper limb of individuals who had a stroke.

\section{Conclusion}

This study found that the analyzed tests are only weakly to moderately correlated, thereby suggesting the need for the use of at least two basic instruments, one to evaluate maximal strength and another to evaluate finger or hand dexterity, for a complete evaluation of hand function, so that the functionality of the hands of people after a stroke can be better described.

\section{Acknowledgments}

The authors express gratitude to the participants of the study. BP Cunha thanks the Sao Paulo State Research Foundation by her doctoral scholarship (FAPESP \# 2012/24426-4).

\section{References}

1. Hendricks HT, van Limbeek J, Geurts AC, Zwarts MJ. Motor recovery after stroke: a systematic review of the literature. Arch Phys Med Rehabil. 2002;83(11):1629-37.

2. Teixeira-Salmela LF, Oliveira ESG, Santana EGS, Resende GPR. Fortalecimento muscular e condicionamento físico em hemiplégicos. Acta Fisiatrica. 2000;7(3):108-18.

3. Cirstea MC, Levin MF. Improvement of arm movement patterns and endpoint control depends on type of feedback during practice in stroke survivors. Neurorehabil Neural Repair. 2007;21(5):398-411.

4. Langhorne P, Coupar F, Pollock A. Motor recovery after stroke: a systematic review. Lancet Neurol. 2009;8(8):741-54.

5. Haaland KY, Harrington DL. Hemispheric control of the initial and corrective components of aiming movements. Neuropsychologia. 1989;27(7):961-9.

6. Hermsdorfer J, Hagl E, Nowak DA, Marquardt C. Grip force control during object manipulation in cerebral stroke. Clin Neurophysiol. 2003;114(5):915-29.

7. Jebsen RH, Griffith ER, Long EW, Fowler R. Function of "normal" hand in stroke patients. Arch Phys Med Rehabil. 1971;52(4):170-4 passim.

8. Sunderland A, Bowers MP, Sluman SM, Wilcock DJ, Ardron ME. Impaired dexterity of the ipsilateral hand after stroke and the relationship to cognitive deficit. Stroke. 1999;30(5):949-55.

9. Freitas SM, Gera G, Scholz JP. Timing variability of reach trajectories in left versus right hemisphere stroke. Brain Res. 2011;1419:19-33.

10. Hermsdorfer J, Blankenfeld H, Goldenberg G. The dependence of ipsilesional aiming deficits on task demands, lesioned hemisphere, and apraxia. Neuropsychologia. 2003;41(12):1628-43.

11. Gama GL, Novaes MM, Itamar C, Franco F, Araújo DP, Galdino GS. Habilidade manual do paciente hemiplégico comparado ao idoso saudável. Rev Neurocienc. 2010;18(4):443-7. 
12. Wang YC, Magasi SR, Bohannon RW, Reuben DB, McCreath HE, Bubela DJ, et al. Assessing dexterity function: a comparison of two alternatives for the NIH Toolbox. J Hand Ther. 2011;24(4):313-20.

13. Jankowska E, Edgley SA. How can corticospinal tract neurons contribute to ipsilateral movements? A question with implications for recovery of motor functions. Neuroscientist. 2006;12(1):67-79.

14. Conforto AB, Santos RL, Farias SN, Marie SK, Mangini N, Cohen LG. Effects of somatosensory stimulation on the excitability of the unaffected hemisphere in chronic stroke patients. Clinics (São Paulo). 2008;63(6):735-40.

15. Voos MC, Ribeiro do Valle LE. Estudo comparativo entre a relação do hemisfério acometido no acidente vascular encefálico e a evolução funcional em indivíduos destros. Rev Bras Fisioter. 2008;12(2):113-20.

16. Beebe JA, Lang CE. Relationships and responsiveness of six upper extremity function tests during the first 6 months of recovery after stroke. J Neurol Phys Ther. 2009;33(2):96-103.

17. Lang CE, Beebe JA. Relating movement control at 9 upper extremity segments to loss of hand function in people with chronic hemiparesis. Neurorehabil Neural Repair. 2007;21(3):279-91.

18. Soares AV, Kerscher C, Uhlig L, Domenech SC, Borges NG. Dinamometria de preensão manual como parâmetro de avaliação funcional do membro superior de pacientes hemiparéticos por acidente vascular cerebral. Fisioter Pesq. 2011;18(4):359-64.

19. Geraldes A, Oliveira A, Albuquerque RB, Carvalho JM, Farinatti PTV. A Força de Preensão Manual é Boa Preditora do Desempenho Funcional de Idosos Frágeis: um Estudo Correlacional Múltiplo. Rev Bras Med Esporte. 2008;14(1):12-6.

20. Guerra RS, Amaral TF. Comparison of hand dynamometers in elderly people. J Nutr Health Aging. 2009;13(10):907-12.

21. Lima KCA, Freitas PB. Avaliação da função manual e da força de preensão palmar máxima em indivíduos com diabetes mellitus. Fisioter. Pesq. 2012;19(1):375-80.

22. Mathiowetz V, Kashman N, Volland G, Weber K, Dowe M, Rogers S. Grip and pinch strength: normative data for adults. Arch Phys Med Rehabil. 1985;66(2):69-74.
23. Cavaco N, Alouche S. Instrumentos de avaliação da função de membros superiores após acidente vascular encefálico: uma revisão sistemática. Fisioter. Pesq. 2010;17:178-83.

24. Freitas PB, Krishnan V, Jaric S. Force coordination in object manipulation. J Hum Kinet. 2008;20:37-51.

25. Lima KCA, Santos RQ Freitas PB. Relação entre a força de preensão palmar máxima e destreza dos dedos em adultos saudáveis: Implicações para a avaliação da função manual. BJMB. 2011;6:1-6.

26. Lima KCA, Francisco MM, Freitas PB. Relação entre os desempenhos em diferentes testes frequentemente utilizados na avaliação da função manual. Fisioter. Mov. 2012;25(3):517-24.

27. Oldfield RC. The assessment and analysis of handedness: the Edinburgh inventory. Neuropsychologia. 1971;9(1):97-113.

28. Chen HM, Chen CC, Hsueh IP, Huang SL, Hsieh CL. Test-retest reproducibility and smallest real difference of 5 hand function tests in patients with stroke. Neurorehabil Neural Repair. 2009;23(5):435-40.

29. Lin KC, Chuang LL, Wu CY, Hsieh YW, Chang WY. Responsiveness and validity of three dexterous function measures in stroke rehabilitation. J Rehabil Res Dev. 2010;47(6):563-71.

30. Bovend'Eerdt TJ, Dawes H, Johansen-Berg H, Wade DT. Evaluation of the Modified Jebsen Test of Hand Function and the University of Maryland Arm Questionnaire for Stroke. Clin Rehabil. 2004;18(2):195-202.

Received in $07 / 21 / 2015$ Recebido em 21/07/2015

Approved in 10/26/2015 Aprovado em 26/10/2015 